\title{
What Architectural Historians can Learn from Augmented Reality Technologies?
}

\author{
Tessa Morrison \\ School of Architecture \& Built Environment \\ The University of Newcastle, Australia, 2308 \\ tessa.morrison@newcastle.edu.au
}

\author{
Ning Gu \\ School of Architecture \& Built Environment \\ The University of Newcastle, Australia, 2308 \\ ning.gu@newcastle.edu.au
}

\begin{abstract}
Architectural historians can often be confronted with want seems to be insurmountable problems when examining buildings in cityscape or the cityscape itself, and often reconstructions of the cityscape can be problematic. Generally when reconstructing an ancient or lost cityscape it is very unlikely that there will be a detailed plan, let alone elevations or sections to assist in the reconstruction. Evidence of the cityscape can exist as recorded descriptions, illustrated landscapes, government records, street plans (which if old plans can sometime conflict with each other), photographs and directories that record the owners and the purpose of each building. From this rudimentary evidence architectural historians attempt to reconstruct changing cityscapes. Visualising architectural ideas and concepts through digital images is now an established architectural practice and with each new development in digital technology new research and design practices have also been developed. 2D drawing and graphic design programs such Corel Draw and Illustrator give architects a tool for simplifying corrections, editing plans and developing professional presentations. However, for the architectural historian these programs provided a unique research tool for historic research. The development of conventional 3D modelling programs such as ArchiCAD brought a new element into architectural historical research. ArchiCAD led to a greater understanding of the spatial arrangements and relationships of individual building. Augmented Reality (AR) system is a technology that can insert digital information into the designers' physical environment. AR appears in literature usually in conjunction with the virtual reality and is an environment where the additional information generated by a computer is inserted into the user's view of a real world scene. This paper examines whether this new technology can enhance studies into architectural history. What can Architectural Historians learn from AR technologies?
\end{abstract}

\section{Augmented Reality. Architectural history.}

\section{VISUALISING ARCHITECTURAL IDEAS IN 2D}

Sydney, Australia is a perfect example of a changing cityscape which has only existed for just over 220 years and has rapidly grown from a tent city of 546 people in 1788 to the modern city it is today of 4.2 million people. In a current project Sydney Cove's architecture is being examined through time. Sydney Cove is the heart of Sydney, the project has divided the Cove into four sites, which neighboured each other, each site is being illustrated using Coral Draw from a fixed point through time, form 1788 to the current time. Surprisingly Sydney's streets are not well documented and the position of some buildings that are long ago demolished can be difficult to ascertain, and are often only known through a record of their destruction to make way for another building.

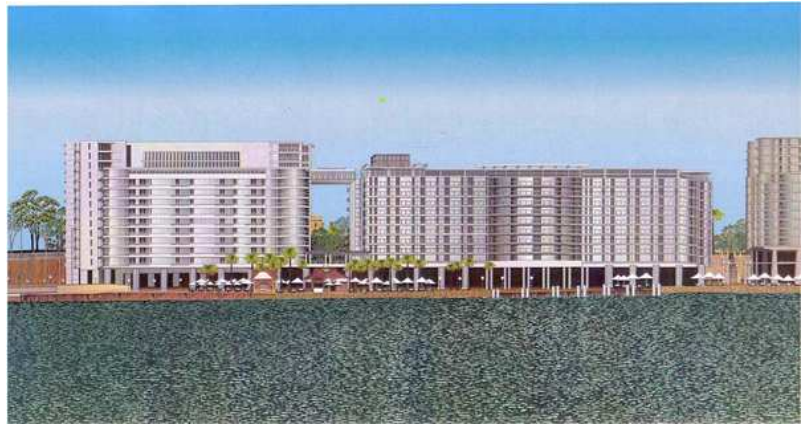

Figure 1: East Circular Quay, Sydney Cove, 2011

By creating a modern site within a 2D drawing and graphic design program it becomes possible to reconstruct the development of the site through time by working backwards, with the aid of archaeological evidence and archival material on architecture such as official documents, correspondence, and requests or contemporary accounts and description of the architecture. Hence 
slowly it becomes possible to reconstruct lost architecture and/or city plans. By examining the space created within this 2D world it is possible to add or subtract buildings to build up a profile of the changing landscape of a site over time. This is a simple but very effective tool in creating the sections of each site from a fixed point, which highlight the changes in a consistent format. However it has its downfalls since only the individual sections are being considered.

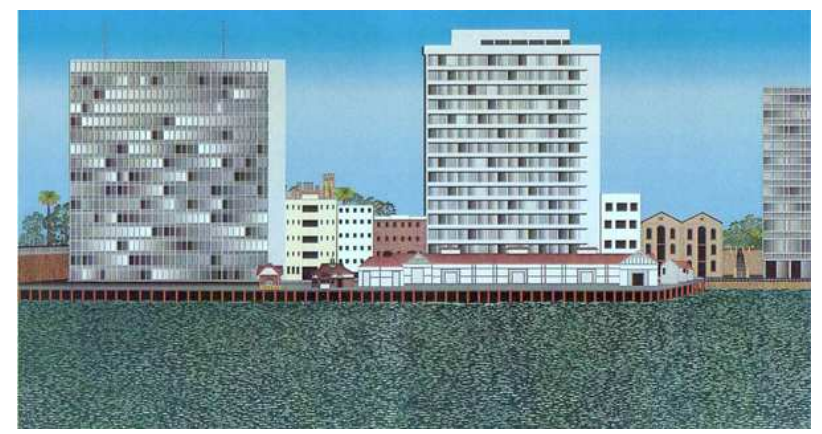

Figure 2: East Circular Quay, Sydney Cove, 1962

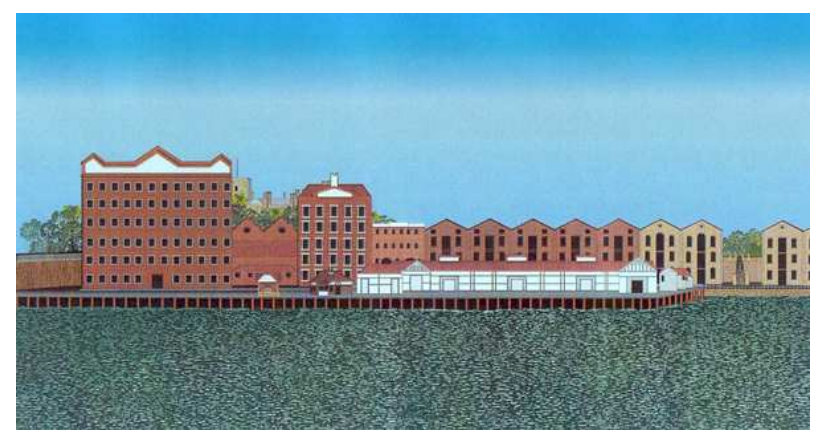

Figure 3: East Circular Quay, Sydney Cove 1950

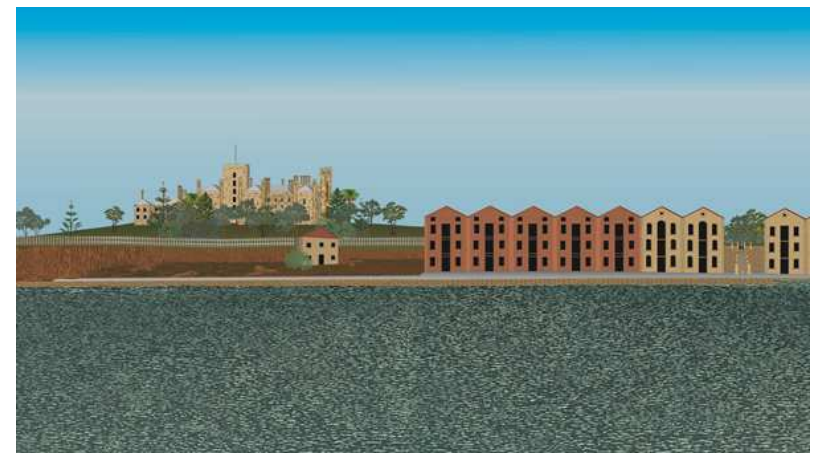

Figure 4: East Circular Quay, Sydney Cove 1875

\section{VISUALISING ARCHITECTURAL IDEAS IN 3D}

Using the same archaeological evidence and archival material it becomes possible to $3 \mathrm{D}$ model buildings or sites through programs such as ArchiCAD, and this led to a more informed understanding of the spatial arrangements and relationships of individual buildings or an archaeological site. An excellent example of this is the reconstruction of Persepolis, by architects Kourosh Afhami and Wolfgand Gambkeat, on display at the British Museum. The reconstruction of Persepolis was an extremely ambitious plan; it was four years in the making and was completed in 2005. This project brought together Afhami's knowledge of the architecture of Persepolis and Gambkeat's expertise in 3D digital technology to create a unique view of Persepolis. This technology turns the archaeological record into an architectural record and through this form of reconstruction by experienced architects it can resolve contradictions that do arise through different interpretations of archaeological evidence.

It resolved problems in the buildings that were not obvious to the archaeologist but was obvious to the architect. The collaboration between archaeologist, or the archaeological record, with architects is not new. Heinrich Schliemann excavator of Troy and Mycenaean in the $19^{\text {th }}$ century worked closely with architects to resolve the problems in understanding the buildings he was excavating. However, in using 3D digital technology to do full reconstructions of cityscapes such as Persepolis rebuilding the excavated section and adding in what is missing by considering the architecture of other sites of the same nation and period - a fuller understanding of the spatial arrangements can be achieved.

An understanding of the spatial arrangements and relationships of individual buildings of an archaeological site using 3D digital technology can more than give a full appreciative of the architecture of that archaeological site. However it can also give an insight into the use of the buildings. By navigating through the reconstruction sense is made of these spatial arrangements that otherwise would not make sense from a floor plan. Ancient art is often very stylized and rituals that are depicted in isolation maybe relatively meaningless or incomprehensible to us but if taken in conjunction with the fully realised architecture or the navigation through it, knowledge of these rituals can be expanded. Rituals and architecture are closely related, each drives the other, and although Afhami and Gambkeat have concentrated on the architecture the flythroughs of their reconstruction on display at the British Museum brings a greater understanding to the artefact on display in the same room. Still images of the reconstruction can be seen at http://www.persepolis3d.de/structur.htm. The propose of this project was for the further understanding of the architectural history of Persepolis but other city reconstructions whose initial purpose was for design and town planning can also assist the architectural historian.

Over ten years ago a 3D virtual survey of Hamburg using ArchiCAD was constructed. It reproduced 
existing buildings, streets, water way etc. This reconstruction was instigated by Marek Kleciak, external counsellor of the Office for Geoinformation and Survey of Hanse city Hamburg, in 1999. Although this survey was for design and planning proposes these reconstructions can benefit architectural history in the same way that the Sydney project does- finding the traces of the old city and working backward with the archival evidence. With 3D modelling the results introduce a different dimension - streets in older cities 'grow' around buildings and natural topology sometimes defined boundaries and/or the architecture. In short it goes beyond the information that a map can product and attempts to replicate the city to assist future planning. In the last ten years the development of 3D virtual survey is not unusual and a quick Google search of 'computer modelling city reconstruction' will result in many amazing reconstructions of ancient and modern cities. Despite the clear benefits to architectural history of such reconstructions such virtual worlds are disconnected from reality.

\section{VISUALISING ARCHITECTURAL IDEAS IN 3D - THREE POTENTIAL SCENARIOS}

Current Human Computer Interaction ( $\mathrm{HCl})$ research focuses on exploring the interactions between the virtual world and the real world, in order to better connect the two by providing the so- called mixed reality where the virtual world and the physical world are seamlessly integrated. Amongst various advancements in the field, $A R$ is a technology that can insert digital information into the designers' physical environment. AR appears in literature usually in conjunction with virtual reality which is an environment where the digital information generated by a computer is inserted into the user's view of a real world scene (Azuma 1997, Barfield \& Caudell 2001). AR can create an immersive augmented environment by inserting digital content into the physical space where people work or live. AR has had a relatively slow transition into the Architecture, Engineering and Construction sector but do include applications in interior design, urban design and planning, mechanical design detailing, and collaborative design. AR technology is envisioned to improve current state-of-the-art of design visualization, review and collaboration. The remaining paper discusses what architectural historians can learn from AR technologies. Three AR scenarios are used as the basis for discussing its potential uses in architectural history: S1) Enhancing architectural drawings and documents by providing corresponding virtual models; S2) Visualizing the 'history' of existing architecture; and S3) Interpreting and exploring architectural designs simultaneously in both the virtual world and the real world.

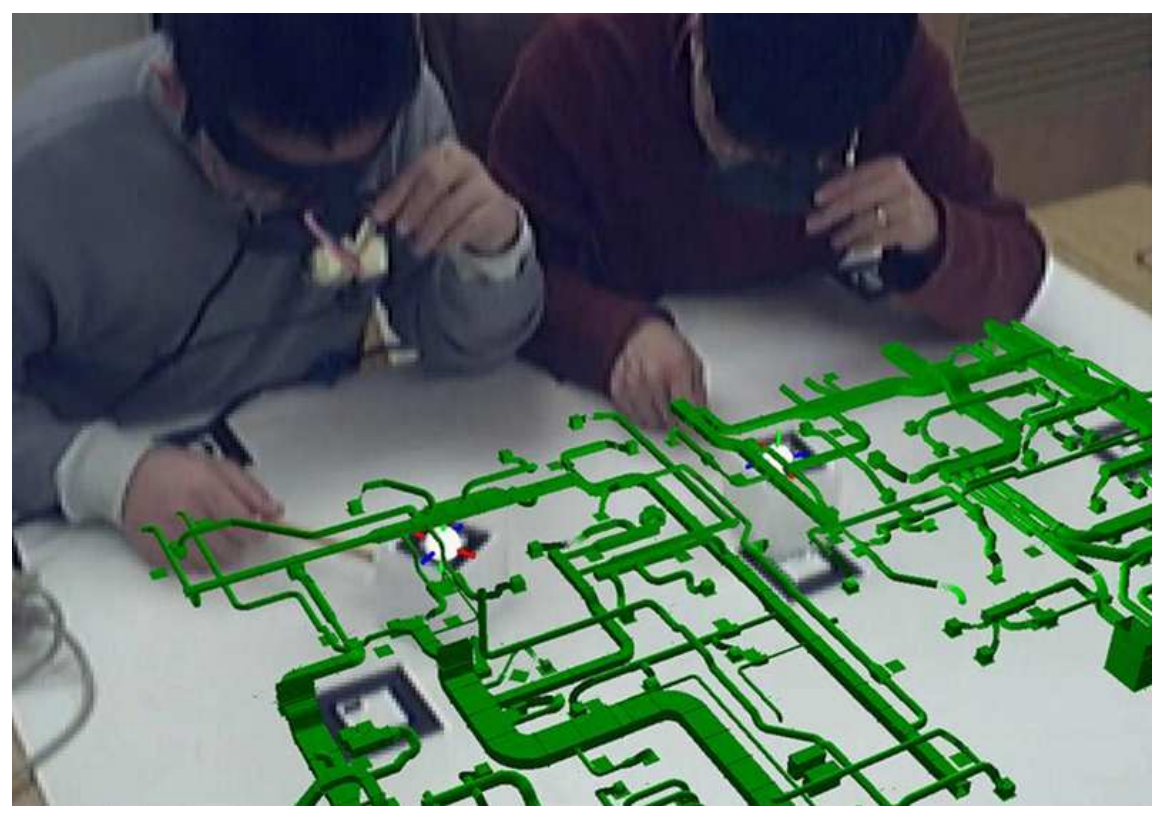

Figure 5: Augmented Reality system for mechanical design review (Wang \& Dunston 2005)

\subsection{SCENARIO ONE}

The Mixed Reality-based Face-to-Face Conferencing System (Wang \& Dunston 2005), is a collaborative virtual environment that creates a face-to-face scenario to support design review collaboration (see Figure 5). The system consists of a central server with CAD application, a client computer with AR rendering software, a headmounted display (HMD) with a colour video camera (real environment sensor) attached, multiple tracking markers, and a tangible interface. The 
HMD, hi-Res800 ${ }^{T M}{ }_{\text {PCHeadset, was used to project }}$ $3 \mathrm{D}$ digital images at a resolution of $800 \times 600$ with \pm 26.5 degree diagonal field of view. Thus, virtual images were overlaid directly on a view of the real world using a see-through HMD. Extending this concept, architectural historians can view the digital models of a historic building while reading the text about that building.

In a grander scale, a virtual reconstruction can be overlaid into the real world site. In an archeologically site this ensures a degree of accuracy of the reconstruction. Although the landscape surrounding the ancient site may have changed over time, generally the topology of the excavated foundations has not changed in their layout and proportion. Thus, overlaying the virtual reconstruction onto a real life site can assist in confirming the accuracy and the architectural feasibility of the reconstruction. Conversely newly planned virtual environment can be projected on to existing historical building. This would greatly assists in the development and planning of historical sensitive areas by making it possible to more accurately monitor the preservation of historic integrity of any future planned development.

\subsection{SCENARIO TWO}

The 'past' of a current building can be viewed through AR and mobile technologies. In 2009, researchers from the Fraunhofer Institute for Computer Graphics Research (IGD) developed a new software which uses AR technology. After downloading the software program through an iphone it allows the user to take photographs from the iphone of the Brandenburg Gate or the Reichstage these photographs integrate with the software. The software blends corresponding historical photographs over the original photo from the iphone. It recognizes these two buildings from any perspective and an image covers the original photo (see Figure 6) with a corresponding perspective of the historic building. If the user moves around the building the corresponding image moves with them.

Although this technology is currently limited to these two buildings its development holds great potential to the architectural historian. Since the inception of photograph 150 years ago many significant building throughout the world have suffered through natural disasters, war damage or 'modernization'; this holistic and corresponding mapping of a building gives a new and very actuate documentation of the building. However, such a visual mapping not only assists in a historic understanding of the building in its changing context and documentation of the building but it also has the potential to be an important tool in assisting future restoration plans. A perfect example for the use of this technology is the Cathedral of Christchurch, New Zealand. After the earthquake of 22/02/11 this historic Cathedral in the heart of Christchurch is to be demolished. By using this technology it will be possible to document of the old Cathedral in conjunction with the new reconstructed Cathedral; therefore preserving the historic architectural record, within one holistic presentation, for future research.

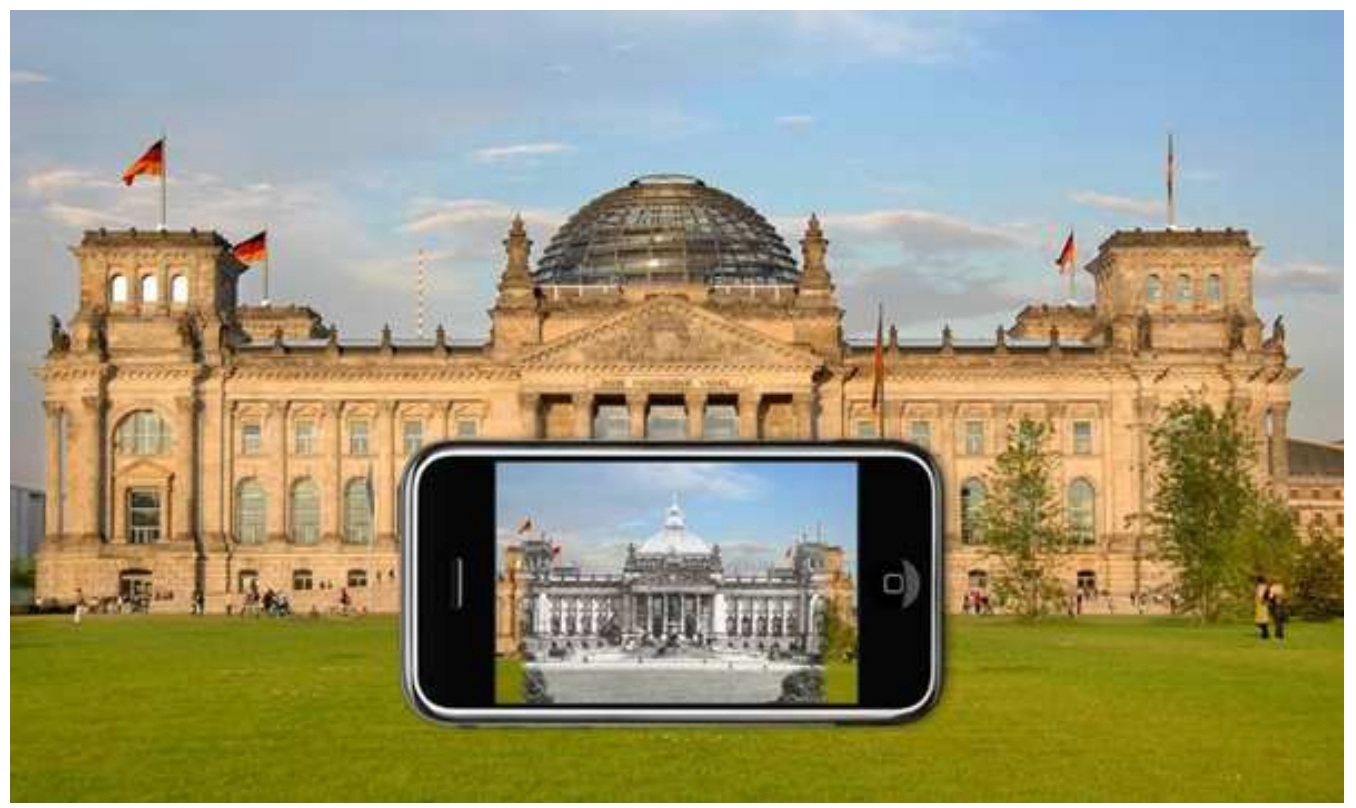

Figure 6: Reichstag past and present (Fraunhofer Institute for Computer Graphics, 2009) 


\subsection{SCENARIO THREE}

The Augmented Reality-based Urban Design System (ARUDesigner) (Wang 2007) was designed to reduce the possibility of misinterpretation among team members by providing more detailed visual information on design objects, and encourages group collaboration and communication in order to improve the design group's overall efficiency and productivity

through the simultaneous interactions in both the virtual worlds and the real worlds (see Figure 7).
Currently the ARUDesigner consists of a PC, a HMD, a video camera as sensing device, and tracking markers. The virtual objects are pre-modeled in ArchiCAD. Using this system, designers are able to modify the layout of the virtual urban models by directly controlling the corresponding physical blocks that are placed in the real design environment. Extending from this concept, architectural historians can apply AR to interpret and explore architectural designs.

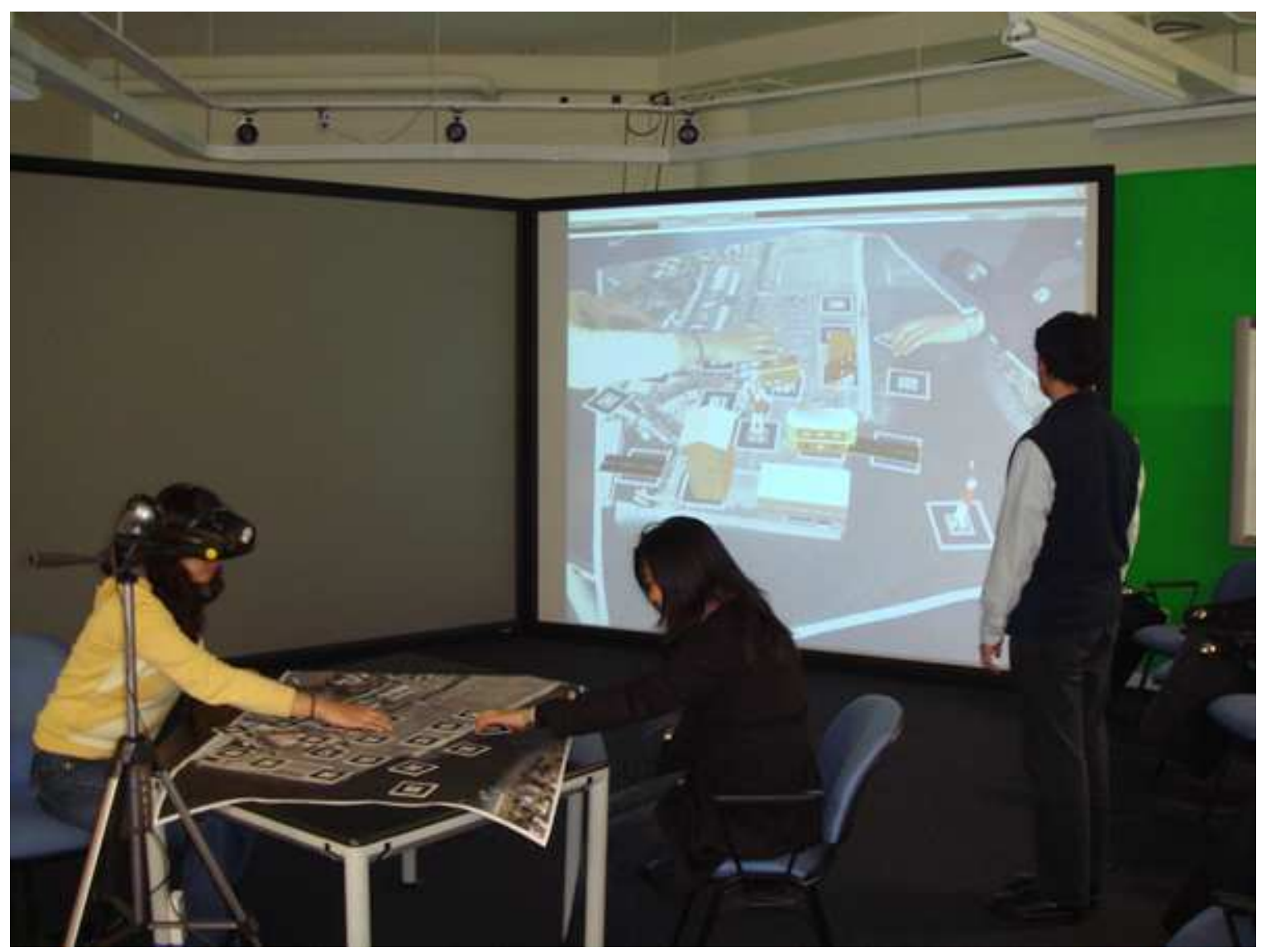

Figure 7: Collaborative research using ARUDesigner for urban planning proposal review simultaneously in both the virtual world and the real world (Wang et al. 2008)

Large reconstructions of ancient sites are generally from collaborative research. ARUDesigner has the potential to simplify the process of the collaboration. As stated in scenario one AR makes it possible to visually map digital reconstructions onto archaeological sites. However, ARUDesigner can take this one step further. It renders possible a 'visual discussion' which can further assisting resolutions of ambiguous architectural areas in the archaeological record, advancing previous methods through the immediacy of this interactive collaborative.

The recent earthquake and tsunamis of 11/03/2011 in North Japan have devastated entire townships. Many historic towns such as Japan's historic fishing port of Hakodate have become a ghost town; the entire town has been demolished by the tsunamis and it will need to be totally rebuilt. ARUDesigner technology has the potential to become an important tool for the planned reconstructions of these townships in North Japan. ARUDesigner could assist this process by allowing a team to consider its plan, the reconstruction of its historic integrity and to advantage future cityscape that are sympathetic to preservation of historic sites and the buildings that remain. The strength of its potential is that it presents a more direct approach to reconstruction - the design process has an immediacy that other processes lack. By moving the 
design elements around and examining the different design combinations with ease, additionally being able to view these combinations in a real environment this will help in the interaction of the team to explore direct options. This can result in better resolutions to design and the preservation or reconstruction of the historic character of the townscape.

\section{CONCLUSION}

AR technologies are in their infancy. Yet they have great potential to assist not only in design and planning but as a tool for architectural historians. It brings in a further aspect to the virtual model that promotes understanding in the relationship of the building and the natural or built topologies. Through the three different methods of using AR technologies discussed in this paper architectural historian can learn and benefit in two distinct and important areas: first the precision of the documentation of buildings and second as a powerful tool in problem solving in the accuracy and the historic integrity of the reconstruction of buildings or cityscapes. Further developments in this technology can only advance and assist the field of architectural history by increasing the understanding of lost or existing historic building in the context of the existing the cityscape.

\section{REFERENCES}

Azuma, R. T. (1997) "A survey of Augmented Reality." Presence: Teleoperators and Virtual Environments, MIT Press. 6 (4), 355-38.

Barfield, W., and Caudell, T. (2001) "Fundamentals of wearable computers and augmented reality." Lawrence Erlbaum Associates, Mahwah, NJ.

http://www.young-germany.de/businesscareer/business-career/article/cebit-2009-iphonebrings-reichstag-back-to-life.html (28 April 2011).

Wang, X. (2007) "Incorporating intelligent agents into augmented reality for urban design." Proceedings of the $12^{\text {th }}$ Conference on Computer-Aided Architectural Design Research in Asia (CAADRIA 2007), April 1922, Nanjing, China, 561-568.

Wang, X. Gu, N. and Marchant, D. (2008) "An empirical study on designers' perceptions of augmented reality within an architectural firm." ITcon. 13 536-552.

Wang, X., and Dunston, P. S. (2005). "System evaluation of a mixed reality-based collaborative prototype for mechanical design review collaboration." CD Proceedings of 2005 ASCE International Conference on Computing in Civil Engineering, Lucio Soibelman and Feniosky Pena-Mora (editors), American Society of Civil Engineers (ASCE), July 1215, Cancun, Mexico. 